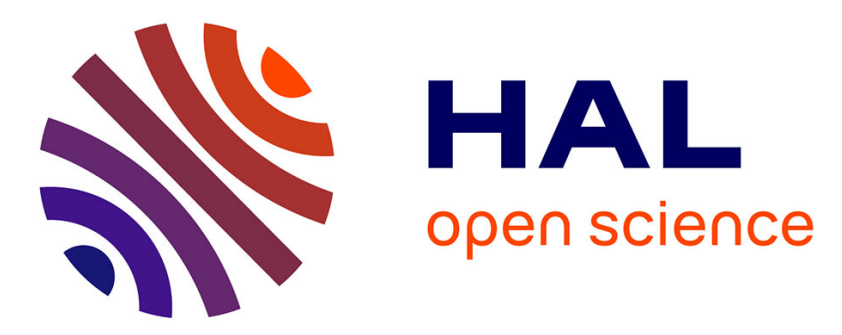

\title{
Low insertion losses and high drop efficiency photonic crystal filter for advanced telecom modulation formats
}

Kevin Lenglé, Laurent Bramerie, Mathilde Gay, Jean-Claude Simon, Sylvain Combrié, Gaëlle Lehoucq, Alfredo de Rossi, Stefania Malaguti, Stefano Trillo, Gaetano Bellanca

\section{To cite this version:}

Kevin Lenglé, Laurent Bramerie, Mathilde Gay, Jean-Claude Simon, Sylvain Combrié, et al.. Low insertion losses and high drop efficiency photonic crystal filter for advanced telecom modulation formats. CLEO: QELS-Fundamental Science, May 2012, San Jose, United States. pp.JW4A.86. hal-00720066

\section{HAL Id: hal-00720066 https://hal.science/hal-00720066}

Submitted on 23 Jul 2012

HAL is a multi-disciplinary open access archive for the deposit and dissemination of scientific research documents, whether they are published or not. The documents may come from teaching and research institutions in France or abroad, or from public or private research centers.
L'archive ouverte pluridisciplinaire HAL, est destinée au dépôt et à la diffusion de documents scientifiques de niveau recherche, publiés ou non, émanant des établissements d'enseignement et de recherche français ou étrangers, des laboratoires publics ou privés. 


\title{
Low insertion losses and high drop efficiency photonic crystal filter for advanced telecom modulation formats
}

\author{
K. Lenglé ${ }^{1,2}$, L. Bramerie ${ }^{1,2}$, M. Gay ${ }^{1,2}$, J.C. Simon ${ }^{1,2}$, S. Combrié ${ }^{3}$, G. Lehoucq ${ }^{3}$, A. De Rossi ${ }^{3}$, S. Malaguti ${ }^{4}$, \\ S. Trillo ${ }^{4}$, G. Bellanca ${ }^{4}$ \\ ${ }^{(1)}$ Universite Europeenne de Bretagne (UEB,) 5 Boulevard Laënnec, 35000 Rennes, France \\ ${ }^{(2)}$ CNRS-Foton Laboratory (UMR 6082), Enssat, BP 80518, 22305 Lannion Cedex, France \\ ${ }^{(3)}$ Thales Research and Technology, 1 Avenue A. Fresnel, 91767 Palaiseau, France \\ ${ }^{(4)}$ University of Ferrara, Via Saragat, 44122 Ferrara, Italy \\ lengle@enssat.fr
}

\begin{abstract}
A 2D photonic crystal 3-ports filter with $6 \mathrm{~dB}$ bus insertion losses and drop efficiency of $47 \%$ is reported. Error-free operation with low penalty $(<0.5 \mathrm{~dB})$ for OOK and DQPSK modulation formats is demonstrated.

OCIS codes: (230.5298) Photonic crystals; (230.7408) Wavelength filtering devices
\end{abstract}

\section{Introduction}

During the last years, photonic crystals $(\mathrm{PhC})$ have been used to realize optical devices for different applications. They have been demonstrated as a promising candidate for realizing large integration scale devices for all-optical communication networks [1-3]. Extremely compact PhC filters for optical communications have been proposed and demonstrated in the literature, with promising results, such as add-drop filter [4], with system assessment at 10 Gbit/s [5], channel drop filter [6-9], bandstop filter [10] and bandpass filter [11]. Here we report on the singlechannel performances and capabilities of PhC-based drop filter, with $28 \mathrm{Gbit} / \mathrm{s}$ OOK (On-Off Keying) signal filtering. Moreover, to the best of our knowledge, we present for the first time, 56 Gbit/s DQPSK (Differential Quadrature Phase Shift Keying) signal filtering through PhC-based filter.

\section{Photonic crystal technology}

The PhC filter is fabricated in III-V material (GaAs) and consists in 3-ports, single resonator design, having a 2D triangular lattice structure [12]. To investigate the filter performance and optimize the different geometrical parameters, Coupled Mode Theory (CMT) and Three Dimensional Finite Difference in the Time Domain (3DFDTD) techniques have been used. As reported in [13], for a single cavity based filter a maximum drop efficiency of $50 \%$ can theoretically be obtained. In this configuration, the achievement of high drop efficiency is pursued by adjusting the transmission properties of the bus and drop waveguides and the cavity to waveguides coupling strength. This modification can be induced, for example, by narrowing the $\mathrm{PhC}$ waveguide (to reduce the cut-off wavelength) or by using a different pitch of the $\mathrm{PhC}$ waveguides in the region close to the resonator (realizing what is usually named a tapered waveguide). If these perturbations are introduced properly, the light at the workingwavelength could be very efficiently switched from bus to drop waveguide.

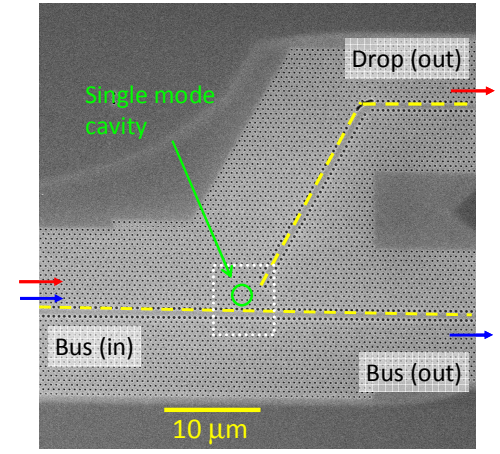

Fig.1. SEM picture of the PhC-based filter with one drop channel

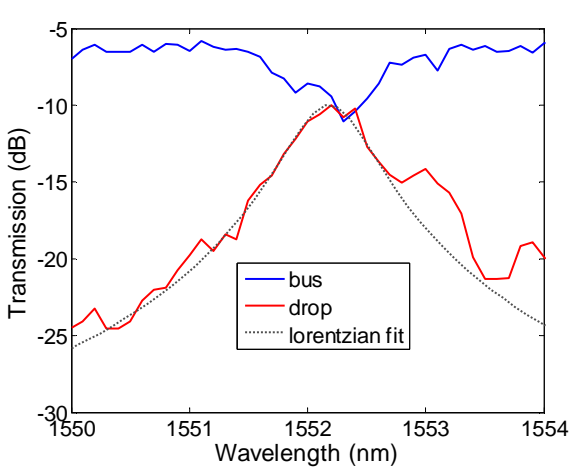

Fig.2. Transmission spectra of bus (blue) and drop (red) ports. Dashed line : Lorentzian fit.

Fig. 1 shows SEM picture of the filter. The single line defect (dotted line) is introduced as a waveguide. The coupling of the cavity (circle) to the waveguide is optimized in order to reach the optimal drop efficiency. In order to reduce the total insertion losses and decrease Fabry-Perot oscillations, we have improved the fiber to PhC coupling using integrated mode adapters [14] (loss $\sim 2.5 \mathrm{~dB}$ per face in TE mode at $1550 \mathrm{~nm}$ ). The total insertion losses, from the input fiber to the output fiber, are of about $10.5 \mathrm{~dB}$ on the drop port and $6 \mathrm{~dB}$ on the bus one. The drop efficiency 
is evaluated to be $47 \%$. The transmission of the drop port is shown on Fig.2. By fitting the transmission curve with a Lorentzian, a $3 \mathrm{~dB}$ bandwidth around $0.8 \mathrm{~nm}$ is measured, as predicted by coupled mode theory. We notice a good fitting on the left side of the resonance but distortions on the right side of the transmission spectrum, which we think to be due to fabrication imperfections. Cross-talk isolation at $500 \mathrm{GHz}$ from central frequency is better than $20 \mathrm{~dB}$.

\section{System assessment}

System assessment was performed using NRZ signal at $28 \mathrm{Gbit} / \mathrm{s}$ and bit error rate (BER) measurement reveals very low penalty $(<0.5 \mathrm{~dB})$ (Fig.3). We also evaluate the possibility to transmit NRZ-DQPSK signal at $56 \mathrm{Gbit} / \mathrm{s}$ into the device, assessed through bit-error rate measurements, revealing very low penalty $(<0.5 \mathrm{~dB})$, at BER of $10^{-9}$, after passing through the device on the drop channel on either the in-phase (I) and the quadrature-phase (Q) component of the DQPSK signal (Fig.3). Additionally, we investigated also the evolution of performances as a function of signal wavelength shift respect to cavity resonance (Fig.4). We can notice penalties when signal is slightly shifted to the right of the resonance, probably due to transmission distortions, and that impact is the same for both modulation formats.

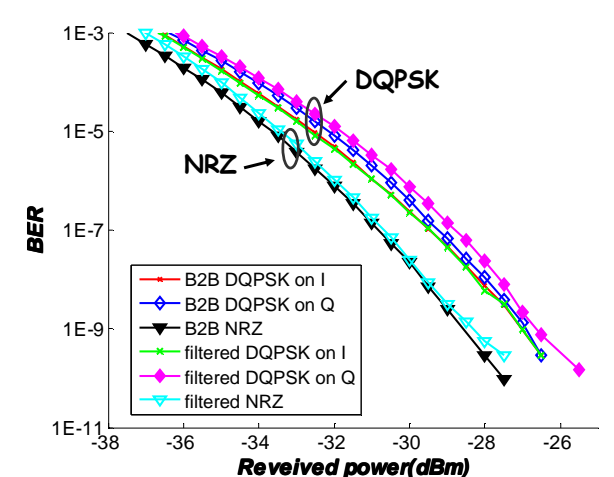

Fig.3. Bit error rate measurements of OOK and DQPSK signals through PhC drop filter.

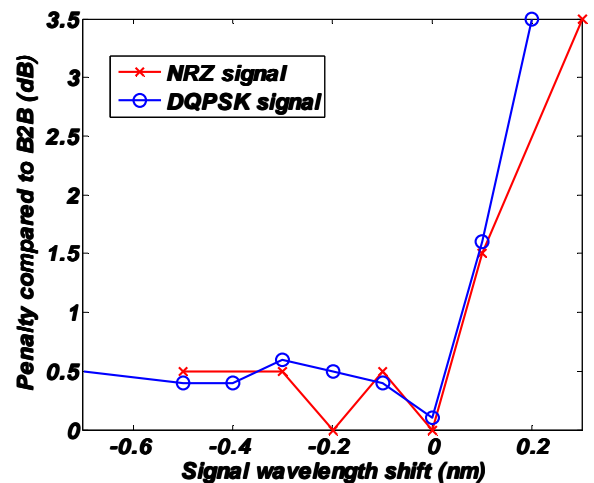

Fig.4. Evolution of penalty as a function of signal wavelength compared to cavity resonance.

\section{Conclusion}

We have developed an optical filters based on semiconductor photonic crystals technology. We have reported the achievement of the lowering of the total insertion losses down to $6 \mathrm{~dB}$ for the bus port and $10.5 \mathrm{~dB}$ for the drop port, the reaching of a drop efficiency up to $47 \%$ and $20 \mathrm{~dB}$ cross-talk isolation (at $500 \mathrm{GHz}$ ). To our knowledge, we have performed for the first time PhC-based filter system assessment through BER measurements with $28 \mathrm{Gbit} / \mathrm{s}$ OOK and $56 \mathrm{Gbit} / \mathrm{s}$ DQPSK data signals, revealing error-free operation with no additional penalty $(<0.5 \mathrm{~dB})$ after the transmission through the drop filter. Additionally, we highlight the impact of transmission distortions in governing the drop filter performances. The results outlined here demonstrate that such a filter has spectral behavior compliant with requirement of coarse-wavelength-division-multiplexing (CWDM) systems.

\section{References}

[1] K. Nozaki et al., "Sub-femtojoule all-optical switching using a photonic-crystal nanocavity", Nature Photon. 4, 477-483 , 2010

[2] B. Corcoran et al., "Ultracompact 160 Gbaud all-optical demultiplexing exploiting slow light in an engineered silicon photonic crystal waveguide", Opt. Lett. 36, No 9 (2011).

[3] A. Shinya et al., "All-optical on-chip bit memory based on ultra high Q InGaAsP photonic crystal”, Opt. Express Vol 16, No 23, 2008

[4] T. Chu et al. "Integrated reconfigurable optical add-drop multiplexer (R-OADM) based on silicon nano-photonic waveguides", IEEE Group IV Photonics Proc., 2006

[5] J.J Vegas Olmos et al., « Photonic add-drop filter based on integrated photonic crystal structures », IEEE JSTQE, vol 16,no 1, 2010

[6] S. Robinson et al., "Channel drop filter based on 2D hetero photonic crystals", Science, Vol.300, pp.1537, 2003

[7] M. David et al., "T-shaped channel drop filters using photonic crystal ring resonators", Physica E, Vol. 40, pp. 3151-3154, 2008

[8] C.C. Wang et al., "Channel drop filters with folded directional couplers in two-dimensional photonic crystals", Physica B, Vol. 405,2010

[9] T. Niemi et al., "Wavelength-division demultiplexing using photonic crystal waveguides", PTL, Vol. 18, pp. 226-228, 2006

[10] F. Monifi et al., "A newbandstop filter based on photonic crystals", Proc. PIER, Cambridge, USA, 2008

[11] C. Chao et al., "Bandpass filters based on phase-shifted photonic crystal waveguide gratings", opt. Express, Vol. 15, no. 18, 2007

[12] S. Combrie et al.,"40Gb/s wavelength division demultiplexing with PhC filter", post deadline proc., MOC'11, Sendai, Japan, 2011

[13] H. Ren et al., "Photonic crystal channel drop filter with a wavelength-selective reflection micro-cavity", Opt. Express, Vol. 14, no 6, 2006

[14] Q. V. Tran et al, « Photonic crystal membrane waveguides with low insertion losses », Appl.Phys.Lett., vol 95, pp. 061105, 2009

\section{Acknowledgement}

We acknowledge the support by the European Union, FP7/ICT funding programme, under the Copernicus project (249012) (www.copernicusproject.eu). This work is also supported by Region Bretagne. 